\title{
On the Utilization of a New Class of School Information Systems School Performance Feedback Systems
}

\author{
Adrie J. Visscher \\ University of Twente, the Netherlands
}

\begin{abstract}
Given the internationally increasing trend to feed back information to schools and teachers on their performance to improve their quality, the characteristics of so-called school performance feedback systems (SPFS) will be analysed here along with the factors which have contributed to their international growth. A theoretical framework is presented which includes the factors assumed to influence the utilisation of SPFS-information. The findings of a longitudinal study into the use of a Dutch SPFS called ZEBO are summarized here, and finally, some reflections are presented on the complexity of SPFS use and on how SPFS utilization may be promoted further.
\end{abstract}

Keywords: School self-evaluation, school improvement, school performance feedback, evaluation utilization

\section{INTRODUCTION}

Internationally seen, there is an increasing trend to feed back information to schools and teachers on their performance. School improvement is often the main objective, however, accountability and the promotion of parental/ student school choice also play a role.

The features of so-called 'school performance feedback systems' (SPFSs) will be analysed here just as the factors that have contributed to their international growth. Thereafter, the characteristics of the Dutch school performance feedback system ZEBO will be presented briefly, followed by the brief presentation of a theoretical framework including the factors assumed to influence the utilisation of SPFS-information and its effects. Based on this framework a longitudinal study into the use of the Dutch SPFS called ZEBO was carried out of which the research findings are summarized here. Finally, some reflections will be presented on why SPFS use is complicated and how the utilization of SPFSs can be promoted further.

Please use the following format when citing this chapter:

Visscher, A.J., 2009, in IFIP International Federation for Information Processing, Volume 292; Evolution of Information Technology in Educational Management; Eds. Tatnall, A., Visscher, A., Finegan, A., O’Mahony, C., (Boston: Springer), pp. 57-67. 


\section{THE NATURE OF SCHOOL PERFORMANCE FEEDBACK SYSTEMS}

School performance feedback systems are defined here as information systems providing schools with confidential information on their performance and functioning as a basis for school self-evaluation. Such systems have become widespread in education in many parts of the world. They share a goal of seeking to maintain and improve the quality of schools, and arise out of a belief in the power of feedback to learn, and to produce change, often accompanied by a sense of disillusionment at the lack of impact of other models of school improvement.

This definition excludes informal, self-generated feedback and separates SPFSs from systems for public school performance accountability and for the support of school choice, which have rather different aims and contents.

The content of the information on the school's performance or functioning must be taken broadly. 'School performance' here is likely to mean some kind of contextualised measure for fair comparison, adjusted to take account of factors beyond the control of the school ('value added'). 'Performance' may also include absolute performance measures and may equally relate to non-academic outcomes of schooling (e.g. behavioural and affective). Information on the 'functioning' of schools relates to school process measures like the resources spent, the subject matter taught, the instructional methods used, and the nature of school leadership etc.

That the feedback should provide a basis for self-evaluation implies that the feedback should not simply be used for self-assessment, but that once such judgements have been made, they ideally lead to some kind of action, e.g. the closer investigation where and why the school under-performs, and the development of a school improvement policy.

\section{REASONS FOR SCHOOL PERFORMANCE FEEDBACK SYSTEMS}

A number of factors seem to have contributed to the growth of formal school performance feedback systems in many countries over the last twenty or so years.

In many western countries in the 1980s and 90 s the rise of a political climate of public sector accountability can be observed. The pressure to evaluate and report on the performance of publicly funded educational institutions did not really lead to SPFSs, however helped to create a climate in which school performance feedback is seen as more salient than previously.

Related to the accountability trend is the trend towards decentralisation in the administration of educational systems. As a result schools are more likely to seek information they can utilise for school quality control, i.e. some sort of SPFS. 
There is moreover some evidence (e.g. Murdoch \& Coe, 1997) that in some countries schools' perceptions of the unfairness of the public judgements of their effectiveness (cf. Visscher, 2001, for an overview of the drawbacks of public school performance indicators) were a factor in their choice to implement a confidential value added school monitoring system. The published school performance information included average raw achievement of a school's students which did not adjust for relevant features of the student intake (e.g. achievement levels of a school's intake). Schools wanted more accurate and fairer data on their own performance - among other things, to be sure about their performance and about whether improvement was really needed or not.

Next, the progress made in research in the twin fields of school effectiveness and school improvement. The former line of research has resulted in a knowledge base (Scheerens \& Bosker, 1997) that can be utilised in developing systems to monitor the quality of schools (e.g. the ZEBO feedback system which will be described below).

School improvement research may have influenced the development of SPFSs too, as scientific activity there showed that educational change initiatives imposed upon schools were often not very successful. Innovation and success are considered much more probable if schools themselves are convinced that something needs to be changed ('ownership'). Receiving information on how your school is doing in comparison with similar schools may be a powerful way to make you aware and determined that something needs to be changed in your organisation.

Dalin (1998), McLaughlin (1998) and Miles (1998) stress the local variability of schools, implying that general, centrally developed policies and reform strategies will not lead to educational change in all schools. Schools are considered to differ so much with respect to their performance levels (and the underlying reasons for them), their innovation capacities and contextual characteristics, that change efforts should take much more account of what is called the 'power of site or place'. Smith (1998) goes a step further. He states that as practitioners know their educational practice best they should state the goals and changes to be worked on and, after extensive training, try to accomplish those. Adaptation to the user-context can then be achieved. A SPFS may a valuable tool within this perspective on school improvement, providing timely, high-quality information on how a school 'is doing' as a basis for practitioner-led improvement actions. That may help practitioners in finding problems in their schools as well as in solving them, before it is too late. An important additional effect may be that practitioners gain a better insight into how their school works (enlightenment) and which interventions work best in their situation.

Related to the pessimism of the school improvement authors is the view of Glass (1979) who regards 'education' as a very complex, highly uncertain and unpredictable system on which we possess only incomplete knowledge. We should not try to find eternal truths about which of several things works well in particular circumstances, as a basis for planning and manipulating 
education at a large distance from the teaching-learning process in schools. What should be done is the diligent monitoring of the system while the services are highly decentralised, the actors are flexible, and can choose from options what they consider best instead of precisely implementing a universal approach that has been developed somewhere at a higher level.

The increase in feedback information to schools has also been influenced by the development of multi-level and value-added data-analysis models which enable the computation of more reliable and valid information on school functioning. The availability of computerised systems for information processing has made a significant contribution to the logistics of school performance feedback (cf. Visscher, Wild \& Fung, 2001).

Last but not least, research results indicate that feedback can be beneficial to future performance. The most comprehensive synthesis of research on feedback effects is Kluger and DeNisi's (1996) meta-analysis. Overall, they found an effect size of 0.41 ( 0.38 after various exclusions), which they interpret as "suggesting that, on average, feedback intervention has a moderate positive effect on performance" (p. 258). However, the wide range of effects found suggested that various features of the feedback, the task to be performed, or its context were significant moderators of the effect. In other words, we should attempt to clarify under what conditions feedback can optimally enhance performance.

\section{AN EXAMPLE: THE DUTCH ZEBO SCHOOL PERFORMANCE FEEDBACK SYSTEM}

ZEBO is an instrument for primary education of which the development took five years. Thirteen school process and classroom process variables (for example, the extent of educational leadership, the achievement orientation of teachers, the way student performance is evaluated, students' time on task, the classroom climate) which had been found in school effectiveness research as correlates of high student performance were selected for the development of ZEBO (Scheerens \& Bosker, 1997). In other words, for each of these variables a scale has been developed to measure the variable and to feed back information on this variable in terms of how the school is doing in comparison with the average Dutch primary school.

After two pilots (in 1997 and 1998), a final field test took place in 1999 in a representative sample of 123 schools in the Netherlands. In 2002, the final market version of ZEBO was released in a computerized form. This format allows schools to use ZEBO whenever they need the information, and they can obtain feedback immediately.

The process variables are measured by means of questionnaires for school management, for teachers and for grade 3-8 pupils. After completing the questionnaires in the schools, schools can generate two kinds of feedback: 
- A school report: One can download graphic and written representations of the results of the school under study in comparison with schools from a national sample on each scale in the school report. Furthermore, the scores of the teachers are compared to the school management scores.

- A classroom report: This report is based on information from the pupil and teacher questionnaires. The results from the students of the school in a certain grade are compared to the results of students in the national sample from that same grade. The responses of the students are also compared to the responses of the teachers.

\section{THE FACTORS SUPPOSED TO MATTER FOR THE SUCCESSFUL IMPLEMENTATION OF SPFSs}

Figure 1 below presents a model depicting the assumed relationships between four groups of factors (Blocks A - D) on the one hand, and the use (Block E) and impact (Block F) of SPFSs on the other. The model is based on a review of the relevant literature (Visscher, 2002).

The Figure shows that the nature and intensity of SPFS use is supposed to be influenced by the SPFS features, which result from its design process. The nature of the implementation process and the organizational characteristics of schools are also supposed to influence SPFS use. The implementation process can promote SPFS use directly (e.g. by supporting schools in accomplishing the innovation), or indirectly (e.g. via training school staff in the required SPFS skills). Finally, the degree of SPFS use, and the way in which it is used, is expected to lead to intended and unintended effects.

It is important to stress that Figure 1 is meant to clarify which factors influence SPFS use and the resultant effects (so Blocks E and F are crucial). In other words, the Figure neither shows how all factors contribute to the effects in Block F nor how other blocks in the Figure are related. If the latter would have been the case, arrows between other blocks could also have been drawn.

Figure 1 also indicates that the school environment plays a role. For example, the extent to which the school board, district and the community play an active role in running schools and demand high school quality may influence to what degree schools use a SPFS to improve performance. If the quality of school functioning is a hot issue, for instance shown by published league tables and 'punishments' for under-performing schools, then schools may be more inclined to improve than when external quality control is only weak, and parents are unable to choose the school of their choice. The educational system can also play a more supporting role by providing schools with the resources required for change and improvement. 
The variables in each of the Blocks in Figure 1 cannot be discussed more in detail here, instead we will focus on reporting the results of a study into the implementation and utilization of the Dutch SPFS called ZEBO (for more details on the backgrounds of the factors the reader can refer to Visscher \& Coe, chapter 5, 2002).

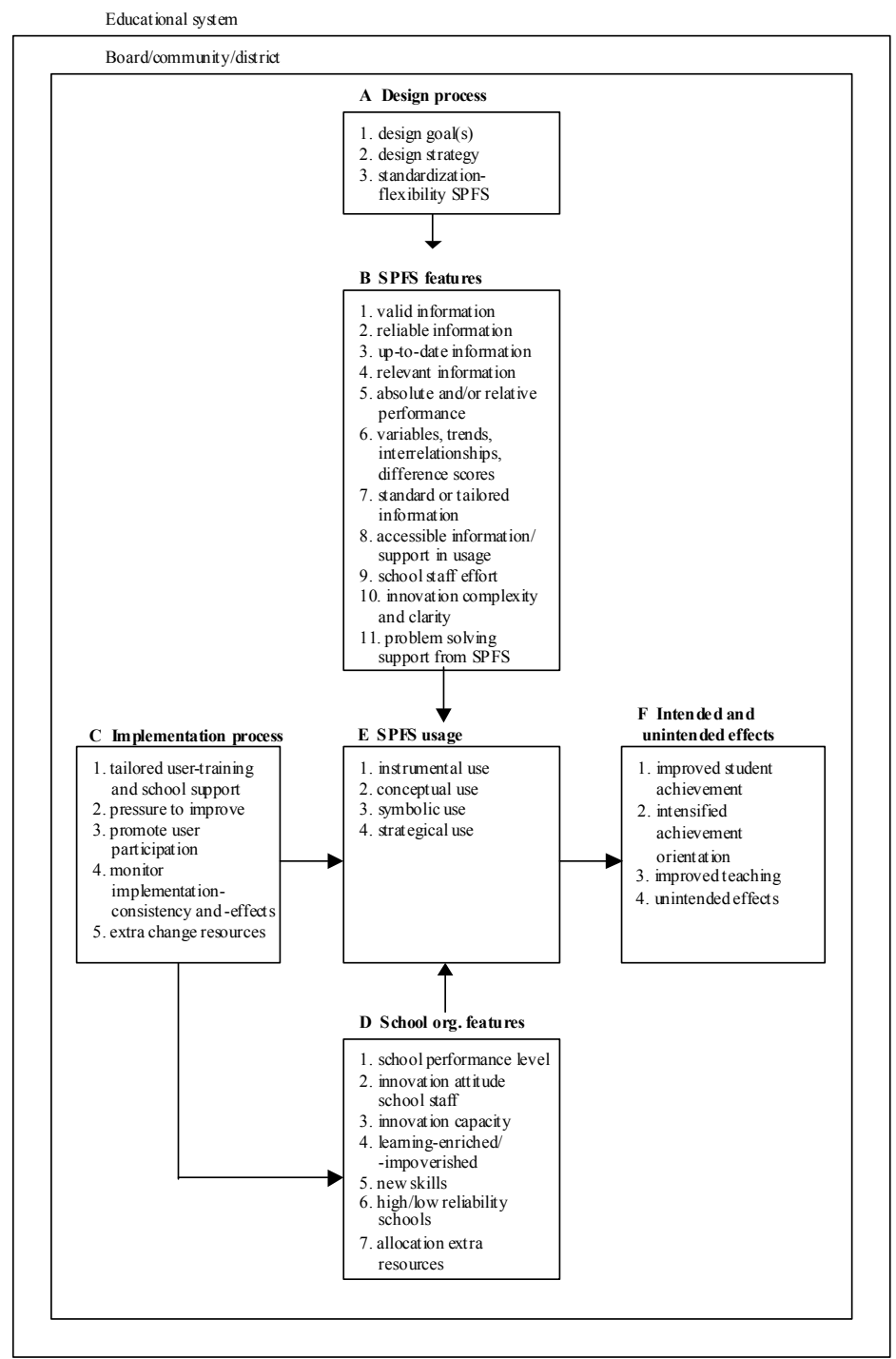

Figure 1: The assumed relationships between the factors influencing SPFS use and effects 


\section{LONGITUDINAL DATA ON THE IMPLEMENTATION OF ZEBO}

From 2003 to 2006 the use of ZEBO has been studied in a group of Dutch project schools (in 2003 the group included 64 primary schools which used ZEBO; in 2006 this number had decreased to 43 schools). School staff filled out questionnaires and interviews were held in a selection of schools; moreover student achievement was measured by means of standardized tests for spelling and mathematics.

The research findings show that the so-called instrumental use (using feedback for improvement-oriented actions) and conceptual use (the feedback influences recipients' ideas but no visible actions) of ZEBO-output are limited especially at the teacher level. About $30 \%$ of the schools use the ZEBO output in the period 2003-2006. In 2003 about $40 \%$ of the teachers did not study the ZEBO output. It was encouraging however that some positive effects of the introduction of ZEBO were observed: better consultation and communication between school staff, and staff paid more attention to quality care and school improvement. Student achievement did not improve in the schools using ZEBO more intensively. Negative effects were not found. Figure 2 below shows which factors especially promoted the use of ZEBO:

- $\quad$ several characteristics of the ZEBO system, e.g. relevant information, ease of use, the time ZEBO use takes, the clarity of the innovation;

- two aspects of the implementation process: training for ZEBO use, and extra resources to use ZEBO;

- four school features: staff's attitudes towards ZEBO, the encouragement to use ZEBO from principal, innovation capacity, and the ZEBO scores in 2003. 


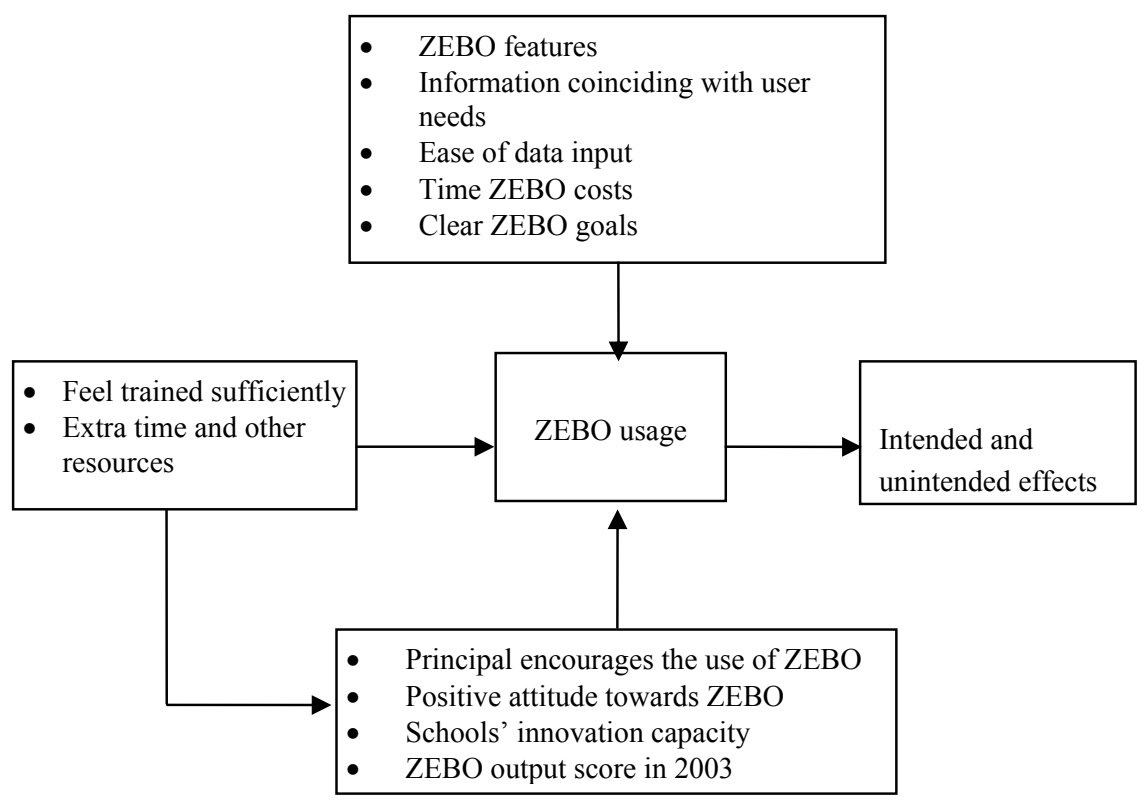

Figure 2: Factors influencing ZEBO use and effects

\section{THE COMPLEXITY OF THE UTILIZATION OF RELEVANT FEEDBACK}

Overall, the level of ZEBO use was still limited in 2006. This finding is not unique as the under-utilization of valuable evaluative data has been observed in many other contexts. Weiss (1998) is one of the most wellknown of the scholars who have written on this topic and based on her long experience she points to several potential problems that may occur when organizations or individuals are provided with evaluative information (like feedback) of which the content is relevant to them as a basis for improving performance.

First of all evaluation results (in our case feedback) may not be disseminated fully among all target users. We saw examples of this in the ZEBO schools: principals who did not distribute the ZEBO feedback to their teachers because the principals did not appreciate the content of the feedback.

Target users also may not understand (e.g. because of the statistics involved in feeding back student achievement data), or believe the feedback and therefore reject or ignore it.

If the feedback is accepted and understood, and it points to underperformance the recipient (the individual teacher, or the school as a whole) may not have an idea of how to improve. However, even if the 
recipient(s) know how to tackle underperformance, other prerequisites for improvement may not be fulfilled: the required skills and resources may be lacking.

One other potential barrier for transforming feedback into performance improvement should be mentioned: the political aspects of performance and improvement. It may, for example, be difficult to openly discuss the poor performance of a colleague, and therefore not be the preferred way to do this.

Reflecting on the utilization of the feedback schools are provided with in many countries nowadays clarifies that instrumental use (the type of information use we expect when we feed back performance information to schools) presupposes a rather complicated set of skills. Schools need to be able to work with ZEBO in terms of entering data and retrieving output. Next they need to posses the skills to interpret the feedback correctly which is not always easy as usually statistics is involved.

If the data has been interpreted and underperformance has been observed somewhere in the school, then the challenge is to find out the cause(s) of the problem and to design and successfully implement a potential remedy. These prerequisites for success will not be fulfilled in many schools.

Moreover, feedback research tells us that the effects of feedback quite heavily depend on the features of the individual who receives the feedback. To what extent is the recipient for example motivated for the goals the feedback refers to (feedback usually shows whether there is a gap between a goal and actual performance), and how motivated is (s)he for using the feedback? The latter will be dependent on the perceived feedback credibility and on the recipient's view on his/her self-efficacy (I can (or cannot) improve performance).

In our view the levers for furthering the use of SPFSs within schools are the provision of the resources required for working with ZEBO (as working with SPFS is time consuming) and the training and support of those who are supposed to benefit from the introduction of SPFSs. If we manage to combine the provision of feedback with the required resources and with tailored training activities (training for the skills to analyse data, diagnose problems, and to design, implement and evaluate remedies), and the support (motivate staff, social support and encouragement form school management) of school staff for working with SPFSs, then we may be able to make a difference. We may then be able to establish a basis for the improvement of processes at school and at classroom level, and via that line it may also be possible, where necessary, to improve the performance of students, teachers and schools.

\section{REFERENCES}

Brophy, J., \& Good, T. (1974). Teacher-pupil relationships. New York: Holt, Rinehart \& Winston. 
Dalin, P. (1998). Developing the twenty-first century school, a challenge to reformers. In A. Hargreaves, A. Lieberman, M. Fullan \& D. Hopkins (Eds.), International Handbook of Educational Change (vol. 5, pp. 10591073). Dordrecht/Boston/London: Kluwer Academic Publishers.

Ehren, M.C.M. (2007). Toezicht en schoolverbetering. [Supervision and school improvement]. Doctoral dissertation. Delft: Eburon.

Fitz-Gibbon, C.T. (2002). A typology of Indicators. In A.J. Visscher. \& R. Coe (Eds.). School improvement through performance feedback. Lisse/Abingdon/Exton/ Tokyo: Swets and Zeitlinger.

Glass, G.V. (1979). Policy for the Unpredictable (Uncertainty Research and Policy). Educational Researcher, 8(9), 12-14.

Huberman, M. (1987). Steps towards an integrated model of research utilization. Knowledge: Creation, Diffusion, Utilization, 8(4), 586-611.

Kluger, A.N., \& DeNisi, A. (1996). The effects of Feedback Interventions on performance: a historical review, a meta-analysis, and a preliminary Feedback Intervention Theory. Psychological Bulletin, 119(2), 254-284.

Maslowski, R., \& Visscher, A.J. (1999a). The potential of formative evaluation in program design models. In J. van den Akker, R.M. Branch, K. Gustafson N. Nieveen, \& Tj. Plomp (Eds.), Design Methodology and Development Research in Education and Training. Dordrecht: Kluwer Academic Publishers.

McLaughlin, M.W. (1998). Listening and learning from the field: tales of policy implementation and situated practice. In A. Hargreaves, A. Lieberman, M. Fullan \& D. Hopkins (Eds.), International Handbook of Educational Change (vol. 5, pp. 70-84). Dordrecht/Boston/London: Kluwer Academic Publishers.

McLaughlin, M.W. (1990). The Rand change agent study revisited; macro perspectives and micro realities, Educational Researcher, 19(9), 11-16.

McPherson, R.B., Crowson, R., \& Pitner, N.J. (1986). Managing Uncertainty: administrative theory and practice in education. Columbus: C.E. Merril Publishing Company.

Miles, M.B. (1998). Finding Keys to School Change: A 40-year Odyssey. In A. Hargreaves, A. Lieberman, M. Fullan \& D. Hopkins (Eds.), International Handbook of Educational Change (vol. 5, pp. 37-39). Dordrecht/ Boston/London: Kluwer Academic Publishers.

Murdoch, K., \& Coe, R. (1997). Working with ALIS: a study of how schools and colleges are using a value added and attitude indicator system. Durham: School of Education, University of Durham, United Kingdom.

Rossi, P.H., \& Freeman, H.E. (1993). Evaluation; a systematic approach. Newbury Park/London/New Delhi: Sage.

Scheerens, J., \& Bosker, R.J. (1997). The foundations of educational effectiveness. Oxford: Elsevier Science Ltd.

Schildkamp, K. (2007). The utilisation of a self-evaluation instrument for primary education. Doctoral dissertation. Enschede: Print Partners Ipskamp.

Smith, P. (1995). On the Unintended Consequences of Publishing Performance Data in the Public Sector. International Journal of Public Administration, 18(2\&3), 277-310. 
Smith, L.M. (1998). A kind of educational idealism: integrating realism and reform. In A. Hargreaves, A. Lieberman, M. Fullan \& D. Hopkins (Eds.), International Handbook of Educational Change (vol. 5, pp. 100-120). Dordrecht/Boston/ London: Kluwer Academic Publishers.

Van Vilsteren, C.A., \& Visscher, A.J. (1987). Schoolwerkplanning: mogelijk in schoolorganisaties? [School work planning: possible in school organisations?] In B. Creemers, J. Giesbers, C. van Vilsteren \& C. van der Perre (Eds.), Handboek Schoolorganisatie en onderwijsmanagement (pp. 6120-6124). Alphen aan den Rijn: Samson.

Visscher, A.J. (2001). Public School Performance Indicators: problems and recommendations. Studies in Educational Evaluation, 27(3), 199-214.

Visscher, A.J. (2002). A framework for studying school performance feedback systems. In A.J. Visscher \& R. Coe (Eds.). School improvement through performance feedback. Lisse/Abingdon/Exton/Tokyo: Swets and Zeitlinger.

Visscher, A.J. \& Coe, R. (2002). Drawing up the balance sheet for school performance feedback systems. In A.J. Visscher \& R. Coe (Eds.). School improvement through performance feedback. Lisse/Abingdon/Exton /Tokyo: Swets and Zeitlinger.

Visscher, A.J., Wild, P., \& Fung, A. (Eds.) (2001). Information Technology in Educational Management; synthesis of experience, research and future perspectives on computer-assisted school information systems. Dordrecht/ Boston/London: Kluwer Academic Publishers.

Weiss, C.H. (1998). Improving the use of evaluations: whose job is it anyway? In A.J. Reynolds \& H.J. Walberg (Eds.), Advances in Educational Productivity, volume 7, pp. 263-276. Greenwich/London: JAI Press.

Whitford, B.L., \& Jones, K. (1998). Assessment and accountability in Kentucky: how high stakes affects teaching and learning. In A. Hargreaves, A. Lieberman, M. Fullan \& D. Hopkins (Eds.), International Handbook of Educational Change (vol. 5, pp. 1163-1178). Dordrecht/Boston/London: Kluwer Academic Publishers. 